\title{
PID BASED HIERARCHICAL AUTONOMOUS SYSTEM PERFORMANCE MAXIMIZATION OF A HYBRID UNMANNED AERIAL VEHICLE (HUAV)
}

\author{
Tuğrul OKTAY ${ }^{1, *}$, Metin UZUN ${ }^{2}$, Harun ÇELİK ${ }^{3}$, Mehmet KONAR ${ }^{3}$ \\ ${ }^{1}$ Department of Aeronautical Engineering, Faculty of Aeronautics and Astronautics, Erciyes University, \\ 38039, Kayseri, Turkey \\ ${ }^{2}$ Department of Aircraft Airframe and Powerpoint, Faculty of Aeronautics and Astronautics, Erciyes University, \\ 38039, Kayseri, Turkey \\ ${ }^{3}$ Department of Aircraft Avionics, Faculty of Aeronautics and Astronautics, Erciyes University, \\ 38039, Kayseri, Turkey
}

\begin{abstract}
In this article, preliminary and conceptual design, dynamic modeling and flight dynamics modes of an unmanned aerial vehicle which have both helicopter flight mode and fixed-wing aircraft flight mode are investigated. The air vehicle (ZANKA-IV) which is planning to be produced in Erciyes University Faculty of Aeronautics and Astronautics Drone Laboratory captures both passive and active morphing properties. Furthermore, this hybrid unmanned aerial vehicle (HUAV) will be controlled by proportional-integral-derivative (PID) controller based autopilot system. In this article, sizes of morphing apparatuses and autonomous system are determined simultaneously in order to maximize autonomous flight performance for the first time. Also, a stochastic optimization method is applied for this simultaneous design. As a result of that, the optimum solution for design parameters is obtained very fast and accurately. Thus, as a result of this approach, autonomous control of HUAV becomes noticeably efficient. Finally, 10\% improvement on autonomous performance index is achieved, and autopilot successfully tracks a reference trajectory with pitching angle of 30 degrees.
\end{abstract}

Keywords: Hybrid UAVs, Autonomous flight, Autonomous performance maximization

\section{INTRODUCTION}

With technological advances in recent years, unmanned aerial vehicles (UAVs) has become increasingly popular in the field of academic research and engineering applications [1-4]. UAVs are performed in many situations of surveillance and analysis such as military applications, airborne mine detection, digital mapping, electronic warfare, radar, saturation, and mixing, recovery, meteorology, aerial photo and video capture, traffic surveillance, small package transportation, scientific research, illegal construction as a fast and secure method [1-4]. These vehicles can be supplied by electric power or liquid fueled, and their height may be as small as a bug while their weight may be large enough to handle thousands of kilograms according to the field of application. As a result of their wide application area, there are various criteria for classification of UAV systems according to flight range, altitude and hover period. UAVs are separated as HALE (high altitude, long endurance UAVS), MALE (medium altitude, long endurance), EN-TUAV (Tactical UAV for long duration cruise, TIHA), LR-TUAV (long range tactical UAV), MR-TUAV (mid-range), SR-TUAV (short-range), CR-TUAV (close range), MUAV (mini), MAV (micro UAV), and vertical take-off and landing (VTOL) UAV [5]. In this article, electric powered and both active and passive morphing CR-VTOL UAV is modeled and simulated. Similarly, IAI Heron [6], served in the Israel army, is known as the most advanced HUAV in the world. However, this HUAV has not any morphing capability. For this reason, it is not possible to run with optimum performance. A small number of HUAV studies also concluded in Turkey (see [7]).

During hover, efficiency of VTOL aircraft is less than the one of helicopter due to the smaller efficient rotor area. However, efficiency of VTOL aircraft during cruise flight is much better than the one of 
helicopters. As an aircraft spend much more time in cruise flight then hover, overall performance of VTOL aircraft is better than helicopter's performance (see [7-8]). Also, VTOL aircrafts are capable of carrying much more load than same size helicopters. Additionally, performance of a helicopter is limited by energy conversion efficiency and lack of resistance to high cruising speed at rotor tips. In contrast to helicopter, VTOL aircraft is not suffered from cruise flight limitations. VTOL UAVs have the ability of both vertical take-off and landing and flying high cruising speeds. Thus, VTOL UAVs are able to takeoff and land in hazardous environments even. Additionally, VTOL UAVs can reach the target work area in a very short time. All these features allow VTOL UAVs to operate with high performance in a wider range of tasks compared to standard and conventional unmanned helicopters as seen in Figure 1.

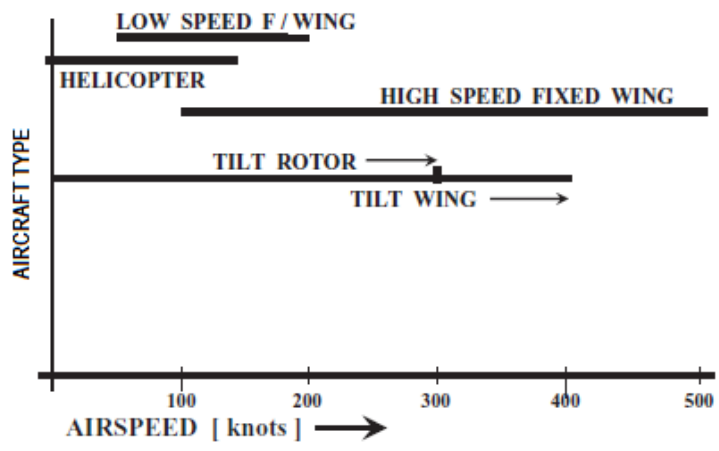

Figure 1. Speed ranges of different aircraft types

For designing an UAV control system, autopilots that help to control UAVs automatically without human assistance during the flight are very important. Autopilots are integrated intelligent systems, and consist of state sensors and controllers. State sensors measure different parameters of UAV continuously by using several sensors such as Global Positioning System (GPS), accelerometer, magnetometer, gyro, and pitot-tube. Control systems use these measurements and calculate differences between current and required conditions.

In this article, a VTOL HUAV called ZANKA-IV that has both passive and active morphing features is modeled at Faculty of Aeronautics and Astronautics, Erciyes University. The drawing of our HUAV is given in Figure 2. Also, dynamic modes of the aircraft are compared to the literature; applied autopilot is mentioned briefly, and the sizes of the morphing mechanisms and PID parameters are optimized by a stochastic optimization method. Moreover, closed-loop simulation results, and improvements on autonomous performance are proposed. A summary of this study was presented and published in a conference [9].

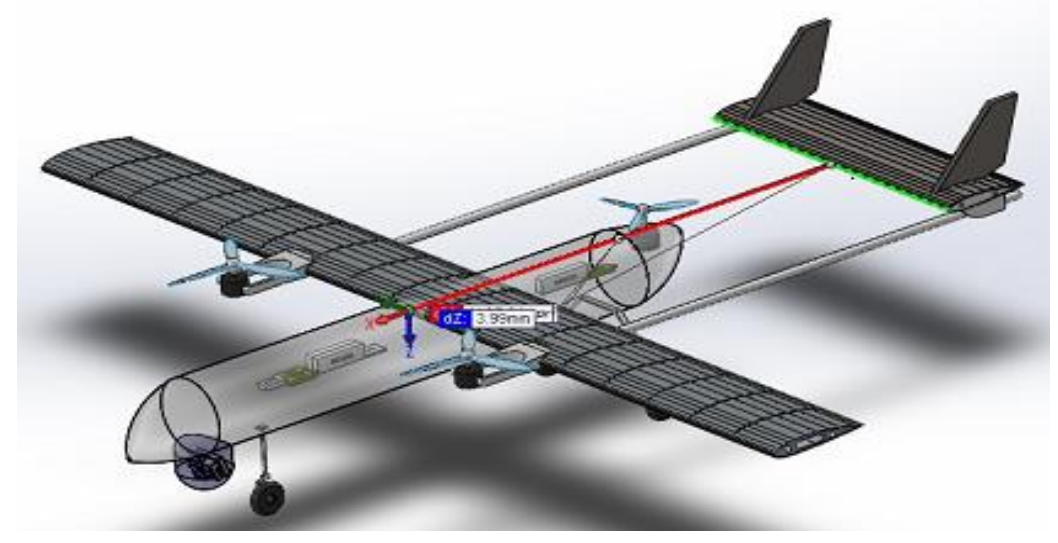

Figure 2. Drawing of the HUAV (ZANKA-IV) 
In this paper, a HUAV is equipped with passive and active morphing features, for the first time in the literature. Also, for the first time, sizes of passive and active morphing mechanisms which let the aircraft better autonomous performance is designed to help maximize autonomous performance. Passive and active morphing provide the some changes in HUAV parameters (e.g., wing, tailplane, etc.). The significant difference between active and passive morphing is that active morphing requires continuous measurements and actuation while passive morphing changes are before the HUAV begins the flight mission or at a separate time during flight. Passive and active morphing parameters as well as the automatic flight control system are optimized simultaneously. For this purpose, simultaneous perturbation stochastic optimization (SPSA) which is an adaptive stochastic optimization method is applied first time. In our HUAV the passively morphing parameters are position of wing and tailplane in longitudinal axis and the actively morphing parameters are extension ratios of wing and horizontal tail (see [10] for details).

\section{MATERIALS AND METHODS}

\subsection{HUAV Dynamics and State-Space Model}

After detailed dynamic modeling process, equations (1) and (2) are presented as longitudinal and lateral state-space parametric models of HUAV, respectively. These equations are also suitable for various HUAV geometries. Reference [11] can be refereed to decide the value of parameters in the matrix. The detailed computation of each parameter is proposed in this reference. These state-space models can be examined for the all flight modes movements except extreme nonlinear behaviors of HUAV. Although there are various references for aircraft modes in the literature such as [11], there is no clear presentation for helicopter state-space modes. In equation (1): $u, w, q$ and $\theta$ indicate longitudinal, vertical and angular velocity of pitching motion, and pitch angle of UAV, and $\delta_{T}$ and $\delta_{e}$ are throttle and elevator control, respectively. In equation (2): $v, p, r$ and $\phi$ denote lateral and angular velocity of rolling motion, angular velocity of yawing motion, roll angle of UAV, and $\delta_{a}$ and $\delta_{r}$ are aileron control and rudder control, respectively.

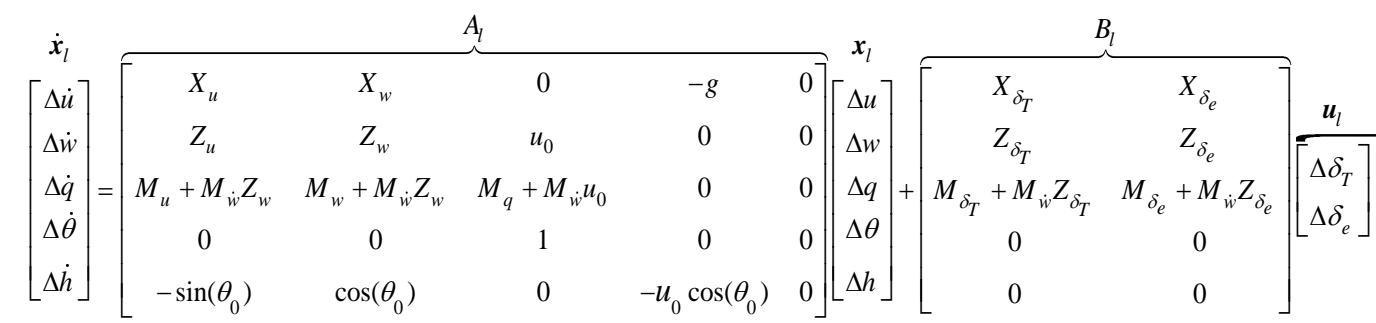

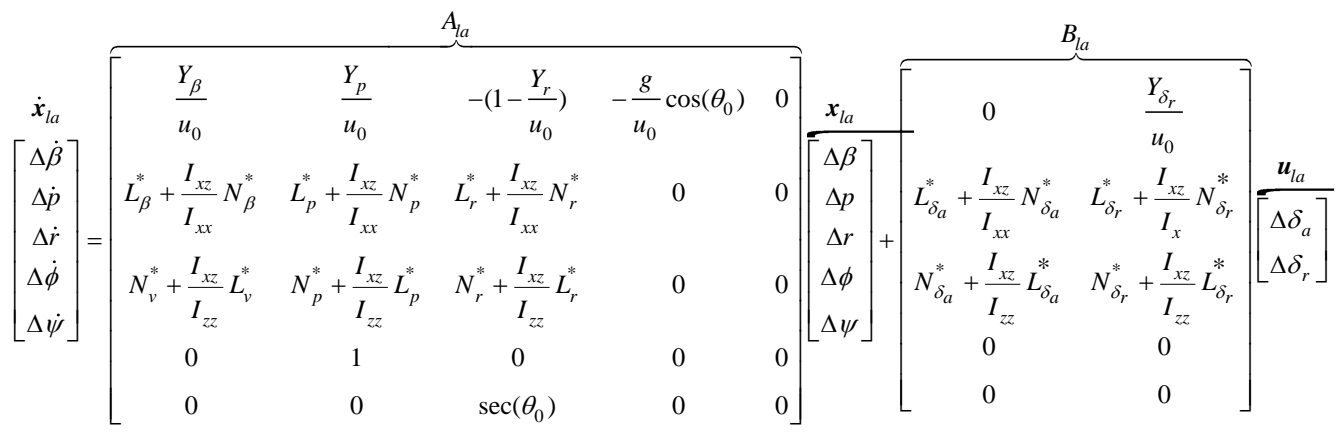

Longitudinal and lateral flight dynamic modes of modeled ZANKA-IV that will be manufactured at Faculty of Aeronautics and Astronautics are shown in Figure 3. These modes are qualitatively and quantitatively similar to the UAV modes in the literature (see [12-14]). Thus, our modeling process is validated. 


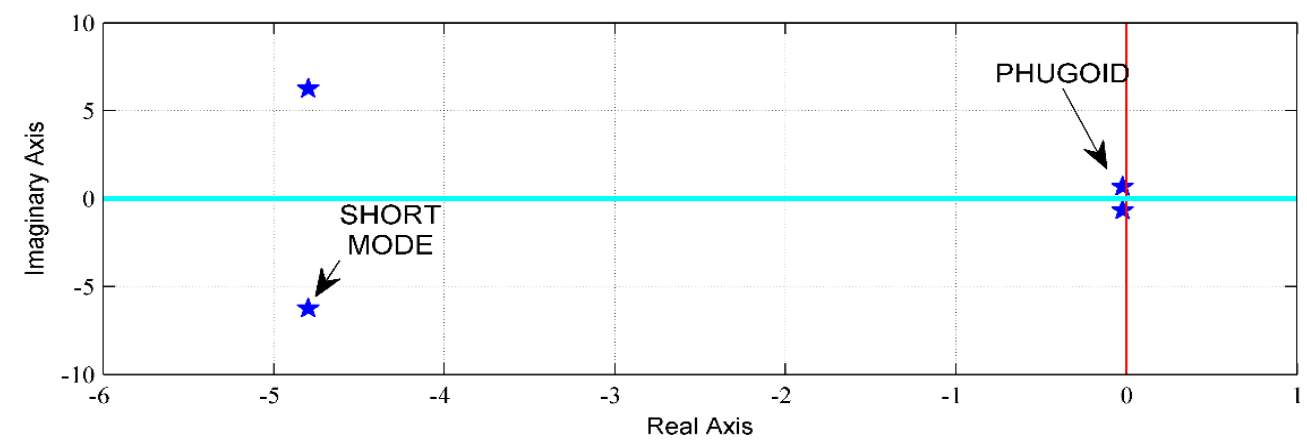

(a)

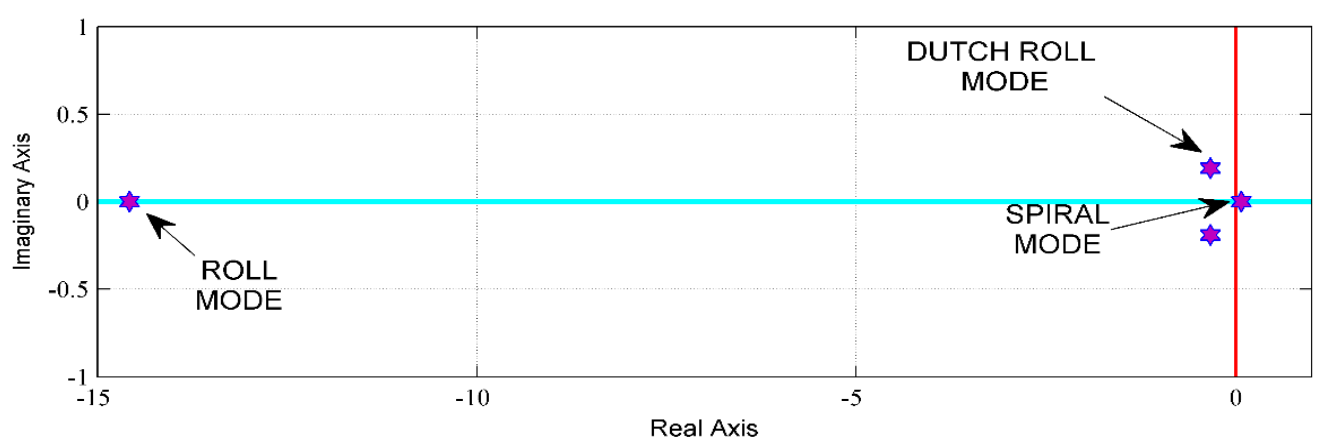

(b)

Figure 3. (a) Longitudinal and (b) lateral flight dynamic modes of ZANKA-IV

\subsection{Hierarchical PID Based Autopilot Structure}

In most general form, PID-based hierarchical autopilot system provides height, yaw angle and velocity tracking. Autopilot system includes six PID controllers in its three layers. These controllers provide trajectory tracking. If users need to utilize all of them, 18 parameters are required to be tuned. However, in this simultaneous design study, there are only two additional structural parameters (assembly points of wing and tail to fuselage). Therefore, the block diagram of the commercial autopilot used in this study is illustrated in Figure 4. More detailed information can be found in References [15, 16].

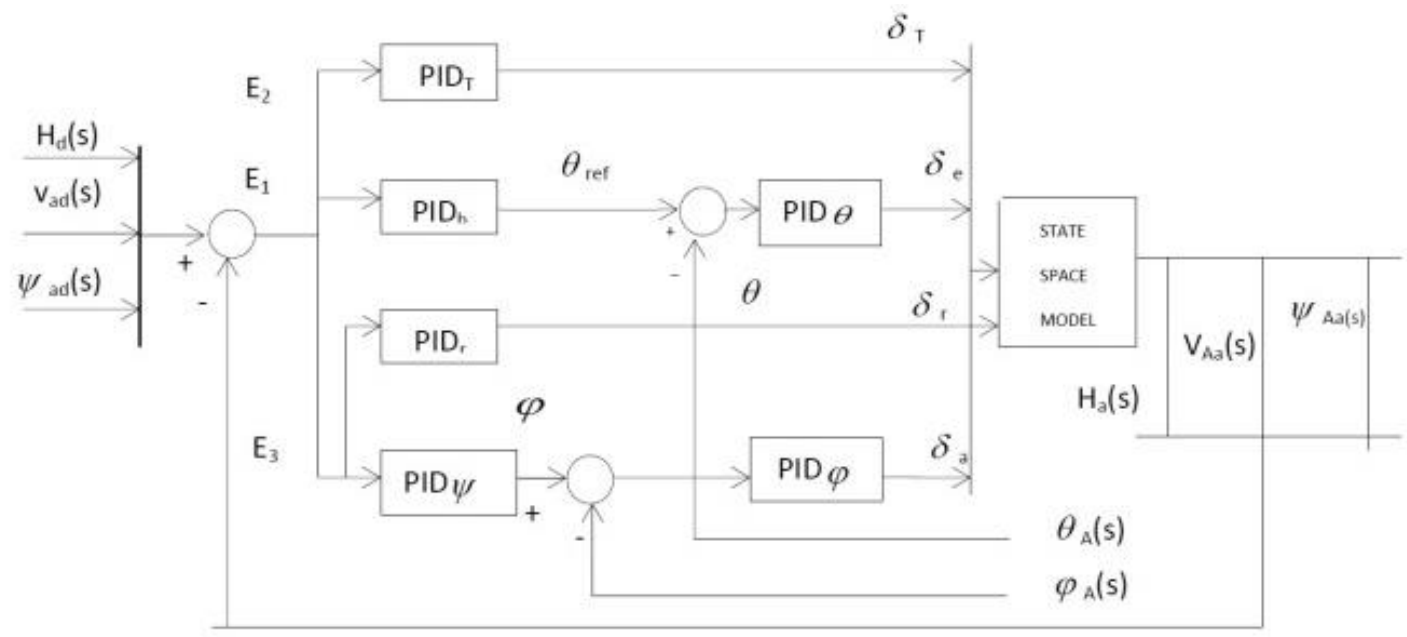

Figure 4. Detailed Block Diagram of the Hierarchical Commercial Autopilot 
It is seen from this block diagram that the hierarchical autopilot system has 6 PID controllers. This autopilot is available to track altitude, velocity, and yaw angle. The $T, h, r, \psi, \theta$, and $\phi$ refer throttle, altitude, rudder, yaw, pitch and roll for PID indices.

\subsection{Problem Formulation}

PID-based hierarchical autopilot system track yaw angle, altitude and velocity generally. Commercial autopilot system accommodates 6 PID controllers in 3 layers (outer, middle and inner layers). These PID controllers have upper and lower limits on the P (proportional), I (integral) and D (differential) parameters. Appropriate estimation of these parameters provides a favorable trajectory tracking. If the autopilot is requested to track yaw angle, altitude and velocity, 18 controlling parameters should be chosen appropriately. In this study, the PID parameters are estimated by SPSA to minimize a cost function. The cost function is consisting of some parameters related to the trajectory tracking (i.e. settling time, rise time and overshoot). If this function becomes minimum, the tracking errors become minimum. Performance means this reality. It is hereby accepted that if performance becomes maximum then energy consumption also reduces. Energy saving is considered with respect to the default initial conditions that $\mathrm{P}=50, \mathrm{I}=5, \mathrm{D}=50$ for PID controller, \%50 spanwise extension for both wing and horizontal tail, and initial longitudinal positions of wing and horizontal tail.

\subsection{Stochastic Optimization Method (SPSA)}

In this paper, SPSA is applied for simultaneous design. According to other optimization methods, SPSA has many advantages. Especially, for highly complicated optimization problems in which the gradient and Hessian is not possible to be calculated analytically (such as in this study), SPSA is able to estimate the optimal solution. With this aspect, it addresses shortcomings of deterministic optimization methods (e.g., golden section search method). It also has the advantage over other stochastic optimization methods. For instance, while genetic algorithms required to calculate $2^{n}$ ( $n$ is the optimization variables) to compute gradient for each iteration, SPSA calculate the gradient just in two steps. Simply, when the number of optimization variables is increased such as to 4 , genetic algorithm makes 16 calculations for optimization at each iteration while SPSA makes 2 calculations only. For this reason, SPSA is much faster to converge an accurate solution. On the other hand, when there are even constrains on the optimization parameters, SPSA can successfully reach optimum solutions.

Because of the very complicated relation between the constraints on the optimization variables and the cost function ( $\mathrm{J}$, see equation 3), the derivatives of the cost function with respect to these variables is not possible to be computed analytically. For this case, stochastic optimization methods are needed to solve this problem. In this study, SPSA is selected because of its previously performance on solving similar constrained optimization problems (see [17-19]).

$$
\boldsymbol{J}=\sum\left(T_{s t}-T_{s t_{u}}\right)^{2}+\left(T_{r t}-T_{r t_{u}}\right)^{2}+\left(\% O S-\% O S_{u}\right)^{2}
$$

where $T_{s t}$ indicates settling time, $T_{r t}$ is rise time, \%OS demonstrates overshoot percentage, and $u$ means upper value of these parameters. Terms of cost function is calculated as below:

If $T_{s t} \geq T_{s t_{u}}, \quad T_{s t}$ is non-defined else

$T_{s t}<T_{s t_{u}}, \quad T_{s t}$ is its value

If $T_{r t} \geq T_{r t_{u}}, \quad T_{r t}$ is non-defined else,

$T_{r t}<T_{r t_{u}}, \quad T_{r t}$ is its value 
If $\% O S \geq \% O S_{u}, \% O S$ is non-defined else

$\% O S<\% O S, \quad \% O S$ is its value.

\subsection{Design Results}

Some geometrical data of ZANKA-IV are shown in Table 1. According to the studies on existing UAVs and consideration of user requests, ZANKA-IV is designed to be weight of $12 \mathrm{~kg}$, carrying a payload weight of $1.5 \mathrm{~kg}$, and endurance of 1.5 hours.

Table1. Initial HUAV Data (ZANKA-IV)

\begin{tabular}{|c|c|c|c|c|c|}
\hline \multirow{4}{*}{ Wing } & Span & Chord Length & Max. Thickness & Mass & Materials used \\
\hline & $b_{w}=250 \mathrm{~cm}$ & $c_{w}=25 \mathrm{~cm}$ & $\delta_{w}=39.27 \mathrm{~mm}$ & $3487.0 \mathrm{gr}$ & $\begin{array}{c}\text { Styrofoam, Balsa, } \\
\text { Carbon Composite, } \\
\text { Carbon Fiber }\end{array}$ \\
\hline & Aspect Ratio & Taper Ratio & Diheral & $\begin{array}{l}\text { Swept } \\
\text { Angle }\end{array}$ & Airfoil \\
\hline & 10 & 1 & 0 degree & 0 degree & NACA 2415 \\
\hline \multirow[b]{2}{*}{ Horizontal Tail } & Span & Chord Length & Max. Thickness & Mass & Materials used \\
\hline & $b_{H T}=80 \mathrm{~cm}$ & $c_{H T}=20 \mathrm{~cm}$ & $\delta_{w}=33.82 \mathrm{~mm}$ & $693.63 \mathrm{gr}$ & $\begin{array}{c}\text { Styrofoam, Balsa, } \\
\text { Carbon,Composite, } \\
\text { Carbon Fiber }\end{array}$ \\
\hline \multirow{2}{*}{ Vertical Tail } & Height & Length (rudderless) & $\begin{array}{l}\text { Length } \\
\text { (including } \\
\text { rudder) } \\
\end{array}$ & Mass & Materials used \\
\hline & $25.38 \mathrm{~cm}$ & $24.96 \mathrm{~cm}$ & $31.55 \mathrm{~cm}$ & $467.37 \mathrm{gr}$ & $\begin{array}{c}\text { Styrofoam, Carbon, } \\
\text { Composite, Carbon } \\
\text { Fiber }\end{array}$ \\
\hline \multirow[b]{2}{*}{$\begin{array}{l}\text { Fuselage (Engine, } \\
\text { landing gear, ESC, } \\
\text { autopilot, etc. } \\
\text { included) }\end{array}$} & Lenght & Max. Depth & Max. Width & Mass & Materials used \\
\hline & $155.32 \mathrm{~cm}$ & $30.0 \mathrm{~cm}$ & $30.0 \mathrm{~cm}$ & $5852.0 \mathrm{gr}$ & $\begin{array}{c}\text { Styrofoam, Balsa, } \\
\text { Carbon Composite, } \\
\text { Carbon Fiber, } \\
\text { Plywood }\end{array}$ \\
\hline
\end{tabular}

The similar HUAVs in the world are compared to ZANKA-IV in Table 2.

Table 2. Comparison of HUAVs

\begin{tabular}{|c|c|c|c|c|}
\hline HUAV & Panther [6] & Mini-Panther [6] & TURAC [7] \\
\hline Fuel Type & Electric & Electric & Electric & Electric \\
\hline Endurance & $6 \mathrm{~h}$ & $1.5 \mathrm{~h}$ & $1.42 \mathrm{~h}$ & $1.5 \mathrm{~h}$ \\
\hline Payload & $8.5 \mathrm{~kg}$ & $1.5 \mathrm{~kg}$ & $8.0 \mathrm{~kg}$ & $1.5 \mathrm{~kg}$ \\
\hline Total weight & $65.0 \mathrm{~kg}$ & $12.0 \mathrm{~kg}$ & $47.0 \mathrm{~kg}$ & $12.0 \mathrm{~kg}$ \\
\hline $\begin{array}{c}\text { Mass of Morphing } \\
\text { Mechanism }\end{array}$ & $\mathrm{X}$ & $\mathrm{X}$ & $\mathrm{X}$ & $0.5 \mathrm{~kg}$ \\
\hline Passive Morphing & $\mathrm{X}$ & $\mathrm{X}$ & $\mathrm{X}$ & $\checkmark$ \\
\hline Active Morphing & $\mathrm{X}$ & $\mathrm{X}$ & $\mathrm{X}$ & $\checkmark$ \\
\hline
\end{tabular}


After estimating PID parameters by SPSA, tracking trajectory of simultaneously designed ZANKA-IV for pitching angle of 30 is given in Figure 5. The exact and relatively improved autonomous performances through simultaneously design are shown in Figures 6 and 7.

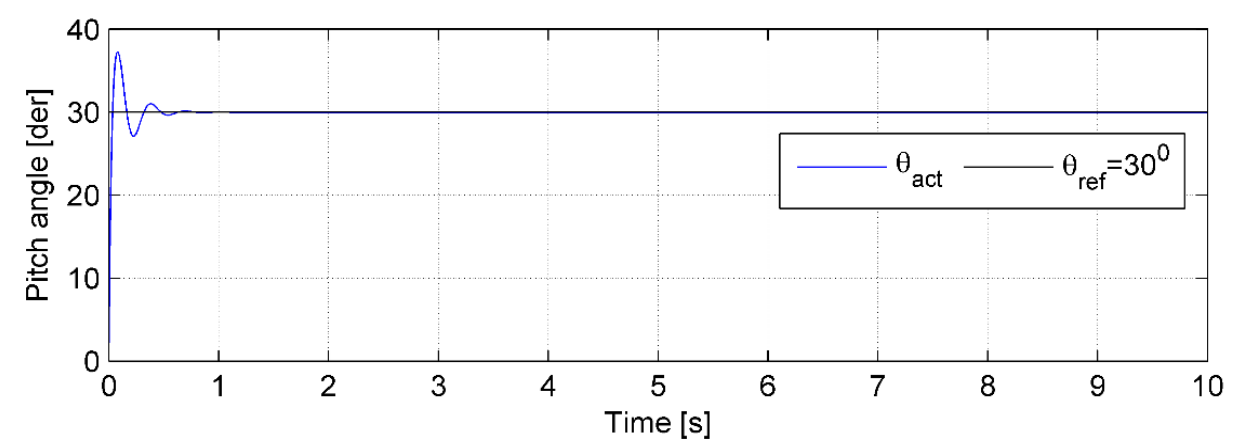

Figure 5. Tracking trajectory for pitching angle through the final optimum solution in the condition without turbulence

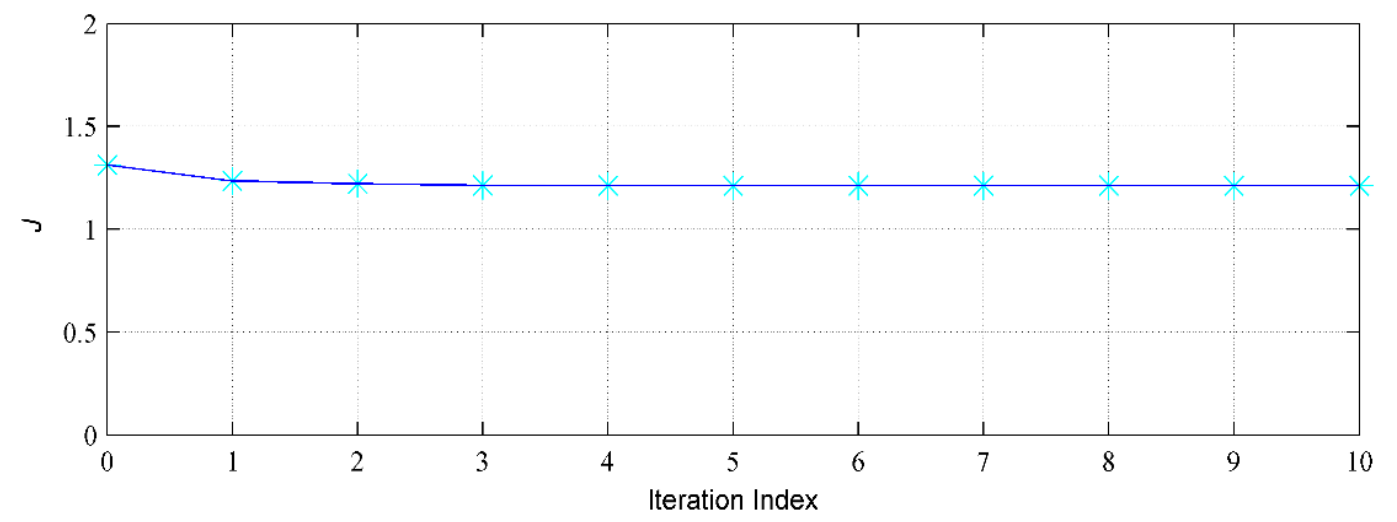

Figure 6. The energy/performance behavior in the optimization steps

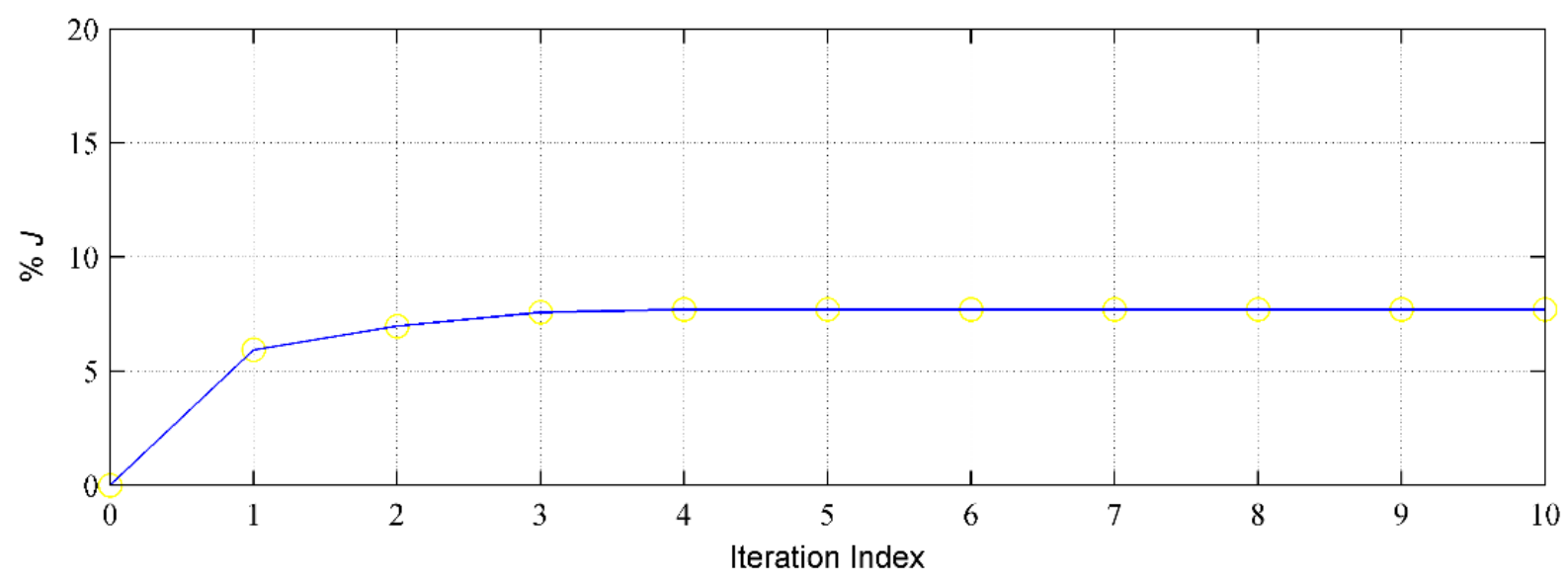

Figure 7. The relative energy/performance improvement behavior in optimization steps

In Figure 8 a brief illustration of morphing mechanism is given. Its working principle can summarized as follows: Our morphing wing or horizontal tail includes reductive micro motor, two equal number of gear teeth, M3 worm gear and bidirectional brushing ESC. A micro motor is a DC motor operating between range of $6 \mathrm{~V}$ to $9 \mathrm{~V}$. A gear motor is mounted to the shaft of this motor. This gear runs 
together with a second gear mounted on a bearing. Interior of the gear mounted on bearing has M3 tooth which is in opened state. Signal sent to ESC through a bistable switch defined on the remote control gives the engine right or left turn. Motor, and therefore mechanical system which move with respect to the direction of rotation of gears lead worm screw in-or-outward. This movement results by moving wing tips parts, produced by outer mold method, over main section. As a result, it provides the change of the wing or horizontal tail area (see [20] for more details).
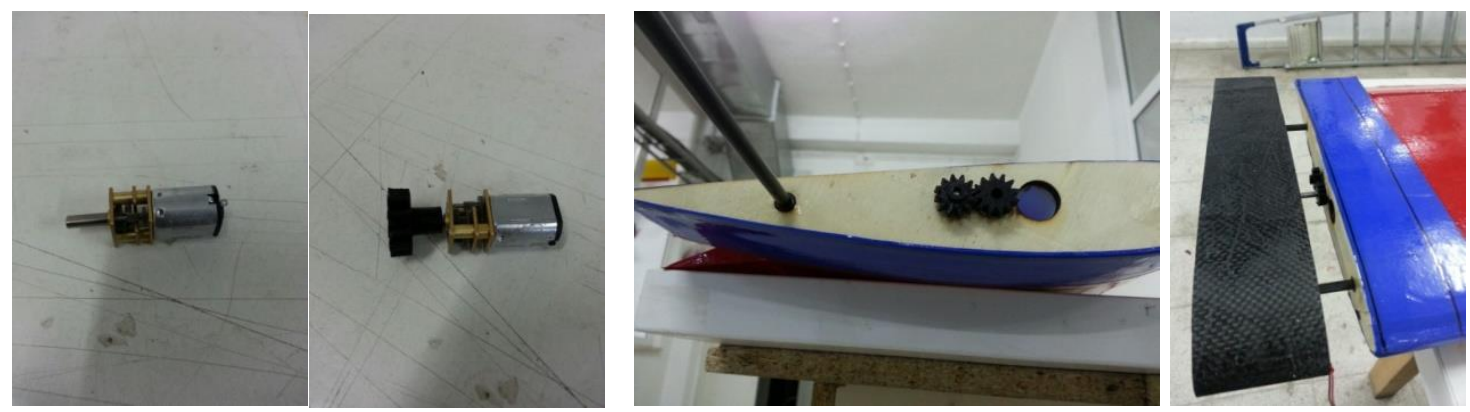

Figure 8. Illustration of morphing mechanism

\section{CONCLUSION}

In this article, initially, preliminary design, dynamic modeling and flight modes of an unmanned air vehicle called ZANKA-IV that has both fixed-wing and helicopter flight mode are investigated. ZANKA-IV which will be manufactured at the Drone Laboratory settled at Erciyes University has passive and active morphing mechanisms. Our HUAV will be controlled automatically by PID-based autopilot system. In this study, the size of morphing mechanisms and autonomous system parameters are firstly simultaneously considered to maximize the autonomous performance of a Hybrid UAV. For this simultaneous design, a stochastic optimization method is utilized to optimize the design parameters. This algorithm provided to converge to the optimum solutions fast. Moreover, through this design approach, a significant amount (approximately 10\%) of energy saving is achieved with respect to the default initial conditions (i.e. $\mathrm{P}=50, \mathrm{I}=5, \mathrm{D}=50$ for PID controller, $\% 50$ spanwise extension for both wing and horizontal tail, and initial longitudinal positions of wing and horizontal tail) by autonomous control of the HUAV. Consequently, the pitching angle of 30 degrees is successfully tracked in simulation environment.

\section{REFERENCES}

[1] Dikmen IC, Arisoy A, Temeltaş H. Dikey İniş-Kalkış Yapabilen Dört Rotorlu Hava Aracının (Quadrotor) Uçuş Kontrolü. Havac1lık ve Uzay Teknolojileri Dergisi 2010; 3: 33-40.

[2] Erdemir S. İHA Sistemlerinde Hava Aracı ve Görev Faydalı Yükleri. ASELSAN 1998; 45.

[3] Celik H, Oktay T, Turkmen I. İnsansiz Küçük Bir Hava Aracının (Zanka-I) Farklı Türbülans Ortamlarinda Model Öngörülü Kontrolü ve Gürbüzlük Testi. Journal of Aeronautics \& Space Technologies 2016; 9(1): 31-42.

[4] Oktay T, Celik H, Turkmen I. Improving Quality of Deblurred Images by Maximizing Autonomous Performance of Fixed-Wing Unmanned Aerial Vehicle. The 9th International Conference on Sustainable Energy \& Environmental Protection; 22-25 September 2016, Kayseri, Turkey.

[5] Bento MDF. Unmanned aerial vehicles: an overview. Inside GNSS, 2008; 3(1): 54-61. 
Oktay et al. / Anadolu Univ. J. of Sci. and Technology A-Appl. Sci. and Eng. 18 (3) - 2017

[6] Wikipedia, http://en.wikipedia.org/wiki/IAI_Panther (accessed 4 October 2016)

[7] Ozdemir U, Aktas YO, Vuruşkan A, Dereli Y, Tarhan A F, Demirbag K, Erdem A, Kalaycioglu GD, Ozkol I, Inalhan G. Design of Commercial Hybrid VTOL UAV System. Journal of Intelligent Robotic Systems 2014; 74: 371-393.

[8] Smith KR, Belina FW. Small V/STOL Aircraft Analysis, NASA Report CR-2425, 1974; 1.

[9] Uzun M, Oktay T, Konar M. İnsansız Hibrid Bir Hava Aracının (HİHA) Otonom Performansının En İyilenmesi. III. Ulusal Havacılık Teknolojisi ve Uygulamaları Kongresi (UHAT 2015); 23-24 October 201, İzmir, Turkey.

[10] Oktay T, Konar M, Abdallah MM, Aydin M, Şal F, Onay M. Autonomous Flight Performance Improvement of Load-Carrying Unmanned Aerial Vehicles by Active Morphing. International Journal of Mechanical, Aerospace, Industrial, Mechatronic and Manufacturing Engineering 2016; 10(1):123-132.

[11] Nelson RC. Flight Stability and Automatic Control. 2nd ed., New York, USA: McGraw-Hill, 2007. pp. 35-234.

[12] Zagi-The original R/C EPP foam wing homepage, http//:www.zagi.com, (accessed 29 October 2015)

[13] Vural SY, Hajiyev C. Autopilot system design for a small unmanned aerial vehicle. MSc, Istanbul Technical University, İstanbul, Turkey, 2008.

[14] Vural SY, Hajiyev C. LQR controller with Kalman estimator applied to UAV longitudinal dynamics. Scientific Research Journal 2013; 4; 36-41.

[15] Jung D, Ratti J, Tsiotras P. Real-time implementation and validation of a new hierarchical path planning scheme of UAVs via hardware-in-the-loop simulation. Journal of Intelligent and Robotic Systems 2009; 54 (1-3): 163-281.

[16] Sartori D. Design, implementation and testing of advanced control laws for fixed-wing UAVs. PhD dissertation, Politecnico di Torino, Italy, 2014.

[17] Oktay T. Constrained control of complex helicopter models. PhD Dissertation, Virginia Tech, USA, 2012.

[18] Oktay T, Sultan C. Simultaneous helicopter and control-system design. Journal of Aircraft 2013; 50 (3): $32-47$.

[19] Sultan C. Proportional damping approximation using the energy gain and simultaneous perturbation stochastic approximation. Mechanical Systems and Signal Processing 2010; 24: 2210-2224.

[20] Oktay T, Konar M, Mohamed AM, Aydin M, Sal F, Onay M, Soylak M. Autonomous flight performance improvement of load-carrying unmanned aerial vehicles by active morphing. International Journal of Mechanical, Aerospace, Industrial, Mechatronic and Manufacturing Engineering, 2016; 10, 1:123-132. 